\title{
Владимир Соловьев и метафизика всеединства
}

\author{
ГАБРИЭЛЛА КИШФАЛЬВИ \\ KISFALVI Gabriella, ELTE Keleti Szláv és Balti Tanszék, Budapest, Múzeum krt. 4/D, H-1088 \\ E-mail: kisfalvigabi@freemail.hu
}

\begin{abstract}
Solovyov's sophiological teaching had a significant influence on the development of Russian philosophy of religion. He contributed a new discovery to the science of sophiology: he threw light on the complicated relationship between the idea of unity originating from God and uniting the whole world, and between the methaphysics of Sophia. The teologeme of Sophia is manifested in Solovyov's philosophical system, in his poetic intuitions and mystical visions as well as in the gnostic texts, in the Kabbala tradition and also in the philosophical and biblical teachings. The Divine Wisdom, as the idea of an endeavour to unity appears in a parallel way with the different aspects of the divine and individual Sophia: such as the divine material, the eternal femininity, the Spirit of the world, the image of ideal humanity etc. The mystery of the Holy Trinity, ie. that God symbolises three persons' unity in love (that of the Father, the Son and the Holy Spirit), the idea and notion of the number three played an important role in the formation of Solovyov's sophiological teaching. All these were instrumental in the formation of his many-sided and complex Sophia-interpretation.

Keywords: Russian philosophy of religion, sophiology, V. Solovyov, Divine Wisdom, the idea of unity, the doctrine of the Holy Trinity
\end{abstract}

Как часть философской концепции идея Софии в России впервые формулируется Владимиром Соловьевым. Он первым создал оригинальную русскую философскую систему и заложил основы цельного, развивающегося и поныне, русского религиозно-философского творчества. Вл. Соловьев внес в софиологию новый элемент, который явился своего рода философским открытием: он установил связь метафизики Софии и метафизики всеединства.

Роль Вл. Соловьева, как пророка Софии, можно понять только в связи с последовавшей за ним эпохой. Можно сказать, что нельзя представить себе более тесной связи, чем Вл. Соловьев и русский религиозно-философский Ренессанс, чем Вл. Соловьев и софиологическая проблематика Серебряного века, мира в предверии и предчувствии катастрофы, апокалипсиса. Хотя ни один из русских философов не признавал себя «безоговорочным последователем» Вл. Соловьева, и он умер одиноким, но - как выше уже приходилось указать - его философская система разными своими аспектами по-разному влияла на учения целого ряда русских философов, в частности, на софиологию о. П. Флоренского, на «эклектическую» софиологию Е. Трубецкого и на наиболее продуманно изложенную софиологию о. С. Булгакова. Однако идеи Вл. Соловьева европейской философией были восприняты как некий запоздавший синтез шеллингианской и гегелианской систем; отсюда последовал вывод, что он не сумел добавить ничего сущест- 
венного к решению тех проблем, которыми тогда занималась европейская мысль. Однако литературно-философское творчество Вл. Соловьева, как мистика и поэта не только в своих стихотворениях, но и в своей философии, повлияло, особенно на младшее поколение символистов, прежде всего на А. Блока, А. Белого и Вяч. Иванова.

Согласно мнению А. Ф. Лосева, все основные идеи Соловьева, среди которых наиболее ценными являются идея Всеединства и Богочеловечества, идея преображения тела и духа, идея Церкви как Тела Христова, вытекали из главной идеии о духовной телесности ${ }^{1}$. Соловьев верил в святость плоти, в божественную материю, в одухотворение материи и материализацию идеи. Однако его «материалистический идеализм», или по термину А. Ф. Лосева, «идеалистический материализм», который С. С. Хоружий называет «религиозным материализмом», явился центром всего соловьевского мировоззрения, никогда не дошел до мистического материализма Достоевского. В рамках этой работы у нас нет возможности для развернутого анализа всем известного культа земли в произведениях Ф. М. Достоевского. Поэтому здесь мы только упомянем, что и Достоевский, и Соловьев пророчествовали о какой-то новой религии, где на первом плане окажется Мать-Земля. Но если у Достоевского осмысливается мистическая аналогия христианскому представлению о Богородице:

Богородица - великая мать сыра земля есть, и великая в том заключается радость. И всякая тоска земная, и всякая слеза земная - радость нам есть, а как напоит слезами под собою землю на поларшина в глубину, то тотчас же о всем и возрадуешься², -

то у Вл. Соловьева, благодаря его постоянной софийной устремленности, появляются материалистические аспекты старых, и языческих и христианских, представлений. Но в почитании «Земли-владычицы», в таинстве которой он увидел сочитание «земной души со светом неземным» ${ }^{3}$, он не зашел так далеко, как его друг Достоевский.

${ }^{1}$ Ср. Лосев А. Ф. Страсть к диалектике. Москва 1990, 191.

2 См. «Бесы», слова старицы в рассказе Хромоножки: Достоевский Ф. М. Полное собрание сочинений, 10. Ленинград 1974, 116. Мы могли бы привести еще множество примеров указаний на мать сырую землю из произведений Достоевского. Ср.: в романе «Братья Карамазовы» следующие слова: «Люби повергаться на землю и лобызать её. Землю целуй и неустанно и ненасытно люби, всех люби, ищи восторга и исступления сего. Омочи землю слезами радости твоея и люби сии слезы твои» (Полное собрание сочинений в 30-и томах, 14. Ленингад 1976, 289). И та же всязь между Богоматерью и Матерью-землею появляется в совете Сони - обратим внимание на выбор имени героини! - к Раскольникову в романе «Преступление и наказание» : «Что делать? воскликнула она, вдруг скочив с места, и глаза её, доселе полные слез, вдруг засверкали. - Встань! (Она схватила его за плечо; он приподнялся, смотря на неё почти в изумлении.) Поди сейчас, сию же минуту, стань на перекрестке, поклонись, поцелуй сначала землю, которую ты осквернил, а потом поклонись всему свету, на все четыре стороны, и скажи всем, вслух: «Я убил!» Тогда бог опять жизни тебе пошлет» (Достоевский Ф. М. Преступление и наказание. Ленинград 1976, 436).

${ }^{3}$ См. стихотворение Вл. Соловьева «Земля-владычица! К тебе чело склонил я...» (1886): Серебряный век. Петербургская поэзия конца XIX — начала XX в. Л., 1991, 50. 
Метафизика всеединства имела долгую философскую историю. Размышляя о ней, следует иметь в виду ранний ее генезис в греческом мифе, в рамках мифотворческого мышления, затем, в частности, систему всеединства Гераклита, Платона, Плотина, понятие всеединства в Новом Завете, идею «плерома душ» Григория Нисского, александрийское учение о всеединстве философа всеединства Джордано Бруно, идею энерийно наполненного всеединства Лейбница, «деконструкцию» всеединства Гегеля, парадигму всеединства Шеллинга, Гуслера, учение О. Конта о человечестве как едином «Великом Существе». Но в русской мысли эта идея появляется впервые отчетливо сформулированной у Вл. Соловьева, который следовал не новозаветной, а платонической традиции ${ }^{4}$, как подчеркивает, в частности, С. С. Хоружий 5 , строя свою софиологическую систему как истинную философию, достаточно основательное философское направление, а не как совокупность неких визионерских, мистических интуиций, гностических фантазий и рационалистических схем. Немаловажно и то обстоятельство, что вся русская метафизика отошла от новоевропейского идеализма и перешла к античному, от Канта и Гегеля к Платону. Платонизм появляется в учениях русских философов, пошедших за Соловьевым, у о. П. Флоренского, С. Булгакова, Е. Трубецкого, Вл. Эрна. В соловьевской философии всеединства, согласно Е. Б. Рашковскому, сочетались строгий библейско-евангельский монотеизм с элементами разнообразных философских культур Запада и Востока. Никто не может сомневаться в том, что альфой и омегой многосторонней соловьевской философии является его понятие о положительном всеединстве. Всеединство - это его девиз, его формула Высшего Начала, Абсолютное есть сущее Всеединое, все в единстве, „отnia simul in uno“, а мир есть становящееся всеединое. Кроме того, понятие всеединства является - согласно мнению С. С. Хоружего - универсальным конструктивным принципом построения его всеохватывающей философской системы, в которой все аспекты (и онтология, и гносеология, и этика и эстетика) подчиняются этому принципу. В своей работе «Общий смысл искусства» Соловьев дает такое определение положительного всеединства:

Достойное, идеальное бытие требует одинакового простора для целого и для частей, следовательно, это не есть свобода от особенностей, а только от их исключительности. Полнота этой свободы требует, чтобы все частные элементы находили себя друг в друге и в целом, каждое полагало себя в другом и другое в себе, ощущало в своей частности единство целого и в целом свою частность, - одним словом, абсолютная солидарность всего существующего, Бог - все во всех.

Полное чувственное осуществление этой всеобщей солидарности или положительного всеединства - совершенная красота не как отражение только идеи от материи, а действительное ее присутствие в материи - предполагает прежде всего глу-

\footnotetext{
${ }^{4}$ Как всем известно, в платоновской философии понятие всеединства формулируется как идеальный прообраз мира, как «мир в Боге».

${ }^{5}$ См. об этом более подробно: Хоружий С. С. После перерыва. Пути русской философии. Спб. 1994, 47-50.
} 
бочайшее и теснейшее взаимодействие между внутренним или духовным и внешним или вещественным бытием 6 .

В качестве противоположности «положительному всеединству», которое и есть сущность Абсолютного как Всеединого Сущего, Соловьев выявляет «отрицательное всеединство», т.е. то отвлеченное, что есть «чистое бытие, равное чистому ничто [...] принцип, с которым нельзя ничего начать и из которого ничего нельзя вывести» ${ }^{2}$. Согласно Соловьеву, это бесплодное всеединство «принцип Гегеля», исходное начало гегелевой логики.

Вл. Соловьев считал себя апостолом свободы. Он выступал в роли религиозного новатора, не терпел ничего слишком правого и ничего слишком левого. В его философии наблюдается синтез разных философских систем, в частности, элементы упомянутых выше платонизма и неоплатонизма, Аристотеля и христианского богословия, патристической философии, гностицизма, Каббалы, философии Лейбница и Канта, Шопенгауэра и Шеллинга, Гегеля, теософии Якоба Бёме, Пордеджа ${ }^{8}$ и Сведенборга, Парацельса и Сен-Мартена. Он никогда не оставался в рамках какой-то одной традиции. Напротив, он всегда реформировал, отвергал или соединял старые концепции. Итак, его текст оказывался в сфере вольного религиозного, внецерковного умозрения, «свободной теософии», по термину Шеллинга. В отличие от православной мысли, которая жила всегда в точно определенной традиции, Соловьев учитывал догматы веры, но не всякий раз соглашался с ними. Об этом свидетельствует и его понятие Софии.

Как отмечается у Соловьева:

«Христос есть единящее начало универсального организма, положительного Все. В этом организме можно, следовательно, различать единство производящее - божественный Логос или Христос, и единство произведенное, воспринимающее единящее действие Логоса» ${ }^{9}$.

Вот это произведенное единство в соловьевской системе и называется библейским именем София. Но наша задача не так проста в определении этого «живого существа». Идея Софии охватывает всю жизнь Соловьева, с детских лет до последнего года его жизни. Соловьев трижды пережил мистическое видение, встречу с самою Софией, которая открывала свои тайны своему рыцарю, влияя на его философскую систему. Ведь впоследствии, то, что он увидел, он истолковал как явле-

\footnotetext{
${ }^{6}$ Соловьев В. С. Сочинения в двух томах, 2. Москва 1988, 395-396. Курсивы все мои $-\Gamma . K$.

${ }^{7}$ Соловьев В. С. Собрание сочинений в 8-и томах, изд. 1, т. 1., Спб., б. г., 22.

${ }^{8}$ Ср.: «Все трое (Гихтель, Арнольд и Пордэдж) имели личный опыт, почти такой же как и мой, и это самое интересное... Я думаю, София возилась с ними больше за их невинность, чем за что-нибудь другое». In: Письма В. С. Соловьева, II, 200. Прочитав русский перевод сочинения «София Вечная Дева Вечной Премудрости, открывшаяся Иоанну Пордечу», Вл. Соловьев называл Дж. Пордеджа (1625-1698), представителя школы «кембриджских неоплатоников» «специалистом по Софии».

${ }^{9}$ Соловьев В. С. Сочинения в 2-х томах, 2. Москва 1989, 108. Курсивы мои - Г. К. 
ние Премудрости Божией. Идея Софии формулируется Владимиром Соловьевым не только в стихотворениях (об этом более развернуто ниже), но особенно в таких его работах, как рукопись на французском языке «Sophie» (1876), «Философские основы цельного знания» (1877), «Чтения о Богочеловечестве» (1877-1881), «Россия и Вселенская Церковь» (1889), «Смысл любви» (1892-1894), «Идея человечества у Августа Конта» (1898), «Три разговора» (1900).

У Вл. Соловьева Премудрость Божия, София явлена под разными ликами: начало человечества, мировая Душа, тело Божие, das EwigWeibliche, Вечная Женственность, Дева Радужных Ворот. Смысловое разнообразие этого понятия сказывается и в том, что София имеет связь с Логосом, но эта связь не значит прямое и однозначное отождествление со Второй Ипостасью. В отношении к Логосу София Вл. Соловьева есть и тело Христово, Церковь. А как женственная личность, преданная Богу, она есть пресвятая Дева Мария, она может принимать лик ангела и т. п. Но прежде всего София играет роль как самостоятельное явление и всегда подчеркивается женский род этого явления.

София как идеальная женственная суть, как идеальная реализация мира в Боге неоднократно подчеркивалась в работах Вл. Соловьева, так же как подчеркивалось и немаловажное свойство Вечной женственности - пассивность: София «это мы с Богом, как Христос есть Бог с нами. Понимаете разницу? Бог с нами, значит, Он активен, а мы пассивны. Он тело, материя, а мы - воля, дух»10. Читая произведения Соловьева, мы часто встречаемся с терминологической неясностью, как и в данном случае: Бог называется телом, материей, однако и София получает название: «тело божие», «материя Божества» ${ }^{11}$. Значит София есть Бог? Нет, речь идет не об этом. Как было уже видно из вышесказанного: согласно Соловьеву, единство произведенное есть София, ибо в божественном организме определяется два единства множества: единство динамическое и единство статическое, т.е. «единство производящее» и «единство произведенное». Как первое единство, Христос есть Логос, как второе, Христос есть София, вследствии чего Христос есть София, но София не есть Христос.

Премудрость Божия проповедовалась Соловьевым как разные типы Софии, но они не всегда различались четко. Прежде всего нам

10 Цитирую по письму Вл. Соловьева, написанному к С. М. Мартыновой от 10 июня 1892 г.: Соловьев С. М. Жизнь и творческая эволюция Владимира Соловьева. Брюссель 1977, 311.

${ }^{11}$ См. Седьмое чтение в «Чтениях о Богочелевечестве»: Собрание сочинений В. С. Соловьева, 3. Брюссель 1966, 115. На этой же странице в сносках Соловьев дает такое объяснение употребляемых им терминов «тело» и «материя» : «Такие слова как «тело» и «материя» мы употребляем здесь, разумеется, лишь в самом общем смысле, как относительные категории, не соединяя с ними тех частных представлений, которые могут иметь место лишь в применении к нашему вещественному миру, но совершенно немыслимы в отношении к Божеству». 
хотелось бы рассмотреть только главные софийные аспекты. Абсолютно божественная София - напоминает нам ту, что определяется в канонической книге Ветхого Завета, Притчи Соломона - где мифологема Софии вводится так:

Господь имел меня началом пути Своего, прежде созданий Своих, искони. От века я помазана, от начала, прежде бытия земли (Притч 8, 30-31).

София как «начало» есть домировая, внемировая, дотварная, предшествующая своим существованием всякой твари, идея Бога еще до природного мира, которую Он осуществлял в своем творчестве как род всеединства. Однако Соловьев говорит не об одной, но о двух Софиях. Божественная, т.е. нетварная София получает воплощение в материальном мире, в чувственном, вещественном, сотворенном теле, и называется Богочеловеческой Софией, в которой сливается одновременно и нетварное и тварное бытие. Когда речь идет о чисто-тварной Софии, в системе Соловьева различаются общекосмический аспект, который содержит в себе благоустроенность космоса, и общечеловеческий аспект, который выдвигает благоустроенность в человечестве. В этом последнем аспекте Софии чувствуется сильное влияние французского философа, О. Конта, основателя позитивизма, который сформулировал свое мнение об общем человечестве и, согласно А. Ф. Лосеву, по образцу французских революционеров назвал его «Великим существом». Здесь нам хотелось бы обратить внимание на два немаловажные обстоятельства. Так же как О. Конт, и Вл. Соловьев говорит о человечестве как о самостоятельном живом существе. Кроме того, по мнению Соловьева, это общечеловеческий организм контовского человечества отождествляется с христианским богочеловечеством, которое есть истинная вера русского народа. Мы согласны с мнением А. Ф. Лосева, по которому в учении Вл. Соловьева здесь начинается настоящая путаница. Соловьев отличает от чисто-идеального понимания христианского богочеловечества в мышлении византийского народа телесночеловеческое понимание Софии русскими, которые строили храмы, посвященные Премудрости Божией, в частности, и в Новгороде, и в Киеве. Чтоб подтвердить свою мысль Соловьев приводит в пример одну древнерусскую икону Софии, которая изображается как центральная женская фигура в царском одеянии, сидящая на престоле; возносится над ней Христос, а в окружении стоят Богородица и Иоанн Креститель. В этой интерпретации видимо путается София тварно-нетварная, Богочеловеческая и София антропологическая.

Играет важную роль то, что О. Конт дал трактовку своего «Великого существа» как женского начала, в котором не только совмещались все умершие и живущие, но оно являлось и матерью, пораждающей человеческие поколения. Безусловно, Вл. Соловьев понимает контовское человечество как Софию и вместе с Контом мыслит о ней как о женском существе, подчеркивая универсально-феминистический характер Софии. Не углубляясь в подробности софиологии Соловьева, 
назовем еще один аспект его Софии - любимый образ Соловьева образ «Жены, облеченной в солнце». Как всем известно, он заимствовал этот образ из новозаветной книги, из «Откровения Иоанна Богослова». Трактуется этот образ Соловьевым то как принцип космической красоты, который приведет весь мир к спасению (ср. формулу Достоевского «Красота спасет мир»), то как Жену, появляющуюся в последние времена, чтоб указать путь после соединения церквей ${ }^{12}$.

Следует еще раз, хотя бы кратко, остановиться на стимулирующей роли троичности (Бог обладает своей единой Премудростью как Отец, как Сын и как Дух Святой), в свете не только произведения «Sophie», но и всех других сочинений Соловьева. Можно сказать, что, по нашему мнению, самый важный соловьевский принцип троичности - это тройное воплощение существенной Премудрости Божией. Имея одну субстанциальную форму, София реализуется то в своем мужском олицетворении, в Иисусе, то в своем женском олицетворени, принимающем имя Марии, то сохраняя собственное имя в олицетворении Церкви.

Так же и «душа мира», как традиционная формула софийной мистики, которая является у Соловьева носительницей, средой реализации Софии, имеет три главных состояния в форме трех времен. Как прошлое души мира понимается ее первоначальное пребывание в единстве Отца, как настоящее определяется ее отделение от Бога (ср. грехопадение души мира в аналогичном соотношении с грехопадением человека!), а как будущее есть ее возвращение к Абсолютному и воссоединение с Ним в совершенном единстве и отождествлении с Софией.

Для понимания софиологической тематики ${ }^{13}$ в философии Вл. Соловьева немаловажное значение имеет его ранний, незавершенный и не опубликованный автором трактат «Sophie», который вышел впервые в свет в Лозанне в 1978 г., а на русском языке был опубликован лишь недавно ${ }^{14}$. Этот философско-мистический набросок пишется им в Лондоне, затем в Каире и в Италии, в Сорренто, куда он переехал из Египта весной 1876 г. В Британском музее Соловьев изучал всю доступную литературу, связанную с индийской, гностической и средневековой философиями; из этого периода сохранились его любопытные записи с упоминанием Каббалы, мистической философии евреев, имен Бёме, Сведенборга, Шеллинга. В это время в письме к отцу Соловьев называет эту свою работу трудом, «малым по объему, но великим по значению», которая получит название, уже в упомянутом письме: «София. Начала вселенской религии», а позже: «София. Начала вселенского

12 Собрание сочинений Владимира Соловьева, 10. Спб. 1911-1913, 218.

13 По историко-философской теории современного немецкого философа М. Френча, софиологическая система Соловьева является вершиной всего предшествующего философского развития. См. об этом более подробно: Бонецкая Н. К истокам софиологии: Вопросы философии 2000/4, 70-80. И также: Френч М. Премудрость в личности: Вопросы философии 2000/4, 80-111.

14 См. в философско-литературном журнале «Логос», 1991-1994/2, 4, 5. 
учения». В диалоге, который ведётся здесь философом с Софией, Соловьев пытается установить синтез не только всех религий, но религии, философии и науки. Этот «первенец» русской софиологии вначале формально оформлен как диалог, но потом он переходит в философское повествование, и - затем - в медиумическое письмо, где сама София водит рукой автора. В этой части рукописи даже и почерк автора совсем изменяется. София открывает свои тайны: «Думай обо мне. $Я$ рожусь в апреле 1878. София», или, см. дальше:

Осборн. Я открою большую тайну. Люди могут господствовать над силами природы, если они решительно откажутся от всех земных целей. Ты ясно, о друг мой, видишь всё, что нужно для этого. Ты должен стараться одолеть Демиурга в себе, чтобы овладеть силой его вне себя (курсив мой. - Г. К.).

В первом тексте Вл. Соловьева, который проложил начало соловьевской софиологии, намечаются разные философские позиции, и набрасываются схемы богословских начал. Используя выражение С. С. Хоружего, можно сказать, что Соловьев «жонглирует» идеями гностицизма и Каббалы (ср. употребление каббалистического термина «Эн Соф»). Кроме этого, мы не должны забывать и того, что в 1875 1876 гг. Соловьев находится также и под влиянием пантеизма ${ }^{15}$. София в учении Соловьева выступает в роли принципа, пытающегося сближать дух и материю, Бога и мир. Если результатом этого сближения является слияние того и другого в одно, то учение Вл. Соловьева достигает степени пантеистических ересев, как это неоднократно находим в его произведении под названием «Sophie».

Учение о трехипостасном строении Абсолюта побудило Соловьева к расшифровыванию троичности в самых разных областях. Прежде всего мы должны заметить, что в «Философских началах цельного знания» (1877) София отождествляется с третьим лицом Пресвятой Троицы, которое называется у Соловьева то «Идеей», то «Сущностью». Это отождествление, с точки зрения христианской догматики, является конечно ересью. Рассматривая произведение «Sophie», в разделении культур Вл. Соловьевым опять можно наблюдать принцип троичности: культуру до Рождества Христова Вл. Соловьев определяет как культуру, основанную на религии Отца, а эпоху после появления Христа как основанную на религии Сына. По мнению Соловьева, после нее должна следовать новая культура, которая, по всей вероятности, будет основываться на религии Святого Духа, точно так, как об этой религии говорили некоторые последующие сторонники Соловьева (в частности, Н. Бердяев $\left.{ }^{16}\right)$. Любопытно заметить, что и в наши времена Католической Церковью понимается деление времени около 2000, «Святого года» на год Отца (1997), на год Сына (1998) и на год Духа Святого (1999)!

15 Более подробно о пантеизме раннего Соловьева см. блестящую работу А. Ф. Лосева: Страсть к диалектике. Москва 1990.

16 См. «Смысл творчества» Н. Бердяева и т.п. 
Также с помощью догмата троичности определяет Вл. Соловьев и три типа людей, которые, - подобно тому, как три ипостаси соединены в едином Боге, но в совершенстве индивидуальны, - и в едином «великом человеке» совмещаются три типа людей, а именно: человек духовный (spirituel), человек разумный (intellectuel, rationnel), человек душевный (animique). По полам они различаются по следующим образом: душевный человек имеет женский пол (!), разумный человек, который является супругом души имеет мужской пол, а Дух, не имея пола, выше всех этих различений.

В этой же рукописи Соловьева выделяется и своеобразная «троичность» в иерархии софийного подчинения, т.е. связи Софии с мужской и женской сферами. На высшей степени иерархии находится София, которой подчиняется все мужское, любящее ее восходящей любовью, а она любит - ответно - нисходящей. Мужской человеческой сфере подчинена вся женская сфера, которая любит восходящей любовью, а мужчины любят женщин нисходящей. Из сказанного выше очевидно, что связь их рассматривается не как «сочинительная», а именно как «подчинительная». Софии мужскому и женскому аспектам подчинены все остальные сферы человеческой жизни, которые тоже подчинены друг другу, получив от Соловьева следующие названия: архиепископы, епископы, деканы, священники, дьяконы, верующие, оглашенные, начинающие. Каждый любит следующего нисходящей любовью, а подчиненный любит восходящей любовью. Таким образом выделяется вертикальная ориентация вселенской любви, состоящей из принципов восходящего и нисходящего.

Далее дается Соловьевым и еще другое различение любви соответственно трем (!) степеням: есть любовь натуральная, основанная на половых отношениях, есть любовь интеллектуальная, охватывающая три следующих степени (патриотизм, любовь к человеку и amor Dei intellectualis), и, наконец, любовь абсолютная, синтез двух предыдущих. Предметом абсолютной любви является София, но теория ее в этом произведении осталась все-таки не продуманной до конца.

Теологема Софии в соловьевской философии вырасла из поэтических интуиций, мистических видений, но обосновывал он ее - это важно еще раз подчеркнуть - одновременно с помощью учений Библии, гностических текстов, каббалистических традиций, разных философских систем (уделяя особое внимание позитивной философии О. Конта, по выражению Е. Б. Рашковского, «восславившего потаенное женственное Grand Être как умопостигаемую суть мира»17 и немецкому идеализму), а также мистиков XVII-XIX вв., в частности, Вл. Соловьев сам указывает на свою зависимость от теософии Я. Бёме, Сведенборга. Мы могли бы еще к ним присоединить и Марсилио Фичино, и Парацельса, и Сен-Мартена. Соловьев нашел присутствие своей Вечной

17 Рашковский Е. Б. Владимир Соловьев, Учение о природе философского знания: Вопросы философии, 1982/6, 87. 
подруги и в произведениях европейских (до позднего Гёте 18 ) и русских поэтов, среди которых особенно выделял Полонского ${ }^{19}$ :

все истинные поэты так или иначе знали и чувствовали «женственную Тень», но немногие ясно говорят о ней; из наших яснее всех - Полонский 20.

Как подчеркивает С. С. Хоружий в своей статье «Идея всеединства от Гераклита до Бахтина» 21 , важнейшую роль играет в философии Соловьева трехипостасное строение Абсолютного: «бытие у него имеет три модуса (воля, представление, чувство), деятельность - три главные сферы (жизнь, знание, творчество), и само положительное всеединство - также три модуса или образа, которые суть Благо, Истина, Красота». Утверждением присутствия в Абсолютном Боге принципа красоты выдвигается вперед и эстетический аспект Софии. Она есть «художница» при Боге, ср. основоположный ветхозаветный текст:

Я родилась [...] кода еще Он не сотворил земли [...] когда Он уготовлял небеса [...] утверждал вверху облака [...] полагал основания земли: тогда я при Нем была художницею, и была радостью всякий день, веселясь пред лицем Его во все время, веселясь на земном кругу Его, и радость моя была с сынами человеческими (Притч 8, 30-31).

Небезразлично и то обстоятельство, что искусство для Соловьева это «вводящее все существующее в форму красоты»22 (принцип красоты это сама София), в нем происходит преображение мира, художество понимается как теургия. Имея отличительной чертой включение в свою философию, кроме мистико-богословского элемента, в частности, и элемента эстетического, Соловьев расшифровывал свою софиологию во все периоды своего творчества как художественное выражение, конкретизация метафизики всеединства.

\footnotetext{
$18 \mathrm{Cp}$. общеизвестную мысль Гёте, выраженную в конце второй части «Фауста», о спасении мира в «Вечноженственном». В произведении Соловьева «Sophie» можно найти перевод из финала «Фауста»: «Женственность вечная всех нас влечет». Однако, у Гёте отмечено нечто иное «zieht uns hinan»!

19 «Царь-Девица» Полонского стало програмным стихотворением для русских символистов!

20 См. статью Вл. Соловьева «Поэзия Я. П. Полонского», напечатанную в литературных приложениях к «Ниве», 1986/2 и 6.

${ }^{21}$ См.: С. С. Хоружий, После перерыва. Пути русской философии. СПб. 1994, 49.

22 Соловьев Вл. С. Собрание сочинений в 8-и томах, изд. 1, т. 1. СПб., б. г., 22. 